\title{
What Kind of Information Society? Introduction to the HCC9 Conference Proceedings
}

\author{
Jacques Berleur $^{1}$, Magda David Hercheui ${ }^{2,3}$, and Lorenz M. Hilty ${ }^{4,5}$ \\ ${ }^{1}$ University of Namur, 61, rue de Bruxelles, 5000 Namur, Belgium \\ ${ }^{2}$ Westminster Business School, 35 Marylebone Road, London, United Kingdom, NW1 5LS \\ ${ }^{3}$ London School of Economics, Houghton Street, London, United Kingdom, WC2A 2AE \\ ${ }^{4}$ University of Zurich, Department of Informatics, Binzmuehlestr. 14, \\ $\mathrm{CH}-8050$ Zurich, Switzerland \\ ${ }^{5}$ Empa, Swiss Federal Laboratories for Materials Science and Technology, Lerchenfeldstr. 5 \\ CH-9014 St.Gallen, Switzerland \\ jberleurainfo.fundp.ac.be, m.hercheui@lse.ac.uk, \\ lorenz.hilty@empa.ch
}

\section{The HCC Conference Series}

The Human Choice and Computers (HCC) conferences organized by the IFIP Technical Committee 9 (TC9) ${ }^{1}$ have been important fora for discussing the impact of Information and Communication Technology (ICT) on society, ranging from the way ICT affect our lives at home and at the workplace to the impact that they have in institutions and communities. These conferences have permitted scholars and practitioners to discuss technology from a social perspective: once we understand that artefacts are not neutral, it becomes necessary to explore their economic, political, cultural, and social implications. In this introduction we recount briefly the history of the HCC conferences, in order to contextualise the contribution made by the HCC 9 and the papers published in this book, a topic discussed in section 2.

The first world conference Human Choice and Computers was held in 1974 (April 1-5) in Vienna [8]. The initiative came from Heinz Zemanek, President of IFIP (19711974), who at the time was also president of IBM Austria. He was supported by Fred Margulies, Secretary of IFAC (International Federation of Automatic Control) who was a main lead in the reflection process launched by trade unions on the computerization of working life. The success of HCC1 was such that IFIP-TC9 henceforth considered it the TC's founding event, if not birthplace. TC9 was conceived in 1976, two years after $\mathrm{HCC} 1$. Its creation was fortunate: having a technical committee reflecting on the issues raised by the nascent Information Technology (IT) was a blessing.

Kelly Gotlieb (CDN) was the first TC9 Chair, and organized HCC2 with Fred Margulies, which took place in Baden (Austria) in 1979 (June 4-8) [7]. It was the first attempt to clarify the field of "Computers and Society". In the proceedings, Abbe Mowshowitz attempted to list the main social issues in computing.

The third world conference HCC3 was held in Stockholm from 2 to 5 September 1985 [10]. Comparative Worldwide National Computer Policies was chosen as its main theme in an attempt to go further in the direction of how various nations were

\footnotetext{
${ }^{1}$ The IFIP Technical Committee 9 (TC9) is dedicated to the study of the relationship of Computers and Society (http://www.ifiptc9.org/).
} 
designing policies on ICT in domains such as working life, public policy, culture, etc. TC9 was chaired at that time by Harold Sackman.

HCC4 took place from 6 to 12 June 1990 in Dublin [2]. It was prepared by TC9, under the chairmanship of Klaus Brunnstein and the European FAST Programme led by Riccardo Petrella. The concept of Technology Assessment applied to the field of Information Technology was surely the first attempt to consolidate the main reflection on social aspects of science in the field of ICT.

The fifth world conference HCC5 was organised in Geneva (August 25-28, 1998) with the help of Silvio Munari and the HEC of the University of Lausanne [9]. It was the first time that TC9 addressed the role of ICT in the context of globalization. Pertti Järvinen was the TC9 Chair.

HCC6 was held in Montreal (August 25-30, 2002) as a track of the $17^{\text {th }}$ IFIP World Computer Congress [5]. The main theme concerned the scope of TC9 as stated in its Aims and Scope: "Issues of Choice and Quality of Life in the Information Society." Klaus Brunnstein and Jacques Berleur, TC9 Chair, were the fathers of that worldwide initiative, organizing as well the IFIP-WG 9.2 Namur Award Ceremony in honour of Deborah Hurley, Director of the Harvard Information Infrastructure Project.

$\mathrm{HCC} 7$, the $7^{\text {th }}$ conference on Human Choice and Computers "Social Informatics: An Information Society for all?", was held in Maribor (Slovenia) on September 2123, 2006 [3]. This conference focused on the concept of social informatics, its methodology and practice, in remembrance of Rob Kling (August 1944 - May 2003). The participants debated this field defined by Rob Kling as the discipline which examines social aspects of computerization - including the roles of information technology in social and organizational change and the ways that the social organization of information technologies are influenced by social forces and social practices.

Participants from all continents gathered at the conference, with speakers coming from 17 different countries. Work was organized in six plenary sessions, nine sessions in five tracks and two panel discussions. A separate part of the conference was the Student forum on Fair Globalisation and ICT based on the syntegration method and created by our Danish colleagues from the Copenhagen Business School (CBS).

The $8^{\text {th }}$ Human Choice and Computers conference, hosted by the University of Pretoria, South Africa (September 25-27, 2008), focused on the social dimensions of ICT policy [1]. Policy plays a major role in the advancement of ICT and the shaping of ICT-mediated socio-economic practice. It also provides mechanisms for addressing potentially undesirable effects of ICT innovation and influences ethical conduct in modern society.

This conference was intended to explore the theoretical justification of policy action concerning ICT and socio-economic change and to discuss particular policies through which various institutions of contemporary governance have sought to promote ICT, to achieve specific socio-economic changes, or to address undesirable effects of ICT diffusion in contemporary society.

Lastly, the $9^{\text {th }}$ Human Choice and Computers International Conference, which is embedded in the $21^{\text {st }}$ World Computer Congress (WCC 2010), is to take place in Brisbane, Australia between 20 and 23 September 2010. In this conference, scholars and practitioners will meet again to discuss what kind of information society we want to strive for. Organized in four tracks, HCC9 will focus on topics related to ethics, 
governance, virtuality, surveillance, privacy, and sustainable development. The section below explains in detail the four tracks of HCC9.

\section{Overview of HCC9}

HCC9 chapters in this book explore topics in relation to the impact of ICTs on society and the importance of the discussion on the right of human choice in developing and adopting technology. The contributions explore theories and perspectives in a variety of domains, pointing out that ICTs are affecting the way we live in society, changing our understanding of identity, our relationships within communities and groups, our interaction with institutions and work places, and our expectations about the future of technology and its impact on societies.

The contributions show we must explore how technology is shaping our lives, and how we as societies want to shape technology and the governance structures related to the development, regulation and use of ICTs. The ethics of the development and use of ICTs continues to be a major area, and one intertwined with the debates on surveillance and privacy. The recent attention Facebook and Google have received from the media and society on related topics shows there is still much to be explored before arriving at a clear norm on how users' privacy should be respected during the handling of their data. Indeed, societies are coming up with new understandings of surveillance and privacy almost every day, either before or after the implementation of technology which changes the status quo. Security issues have been strong arguments for adopting surveillance technologies, but we must also take a critical look at the impact of such choices in society and individuals, in order to be sure we are making informed decisions.

Lastly, ICTs may have a role to play in fostering international development and sustainable development, but this expectation has to be verified in practice. In other words, ICTs have the potential to bring such benefits, but we have to consider the contexts in which such technologies are developed and diffused, in order to ensure we will be able to extract their potential benefits.

In the subsections below we introduce the rationale of each HCC9 track. These introductions are intended to serve the reader as a starting point to understand the selection of articles which contribute to part 1 in this volume.

\subsection{Ethics and ICT Governance}

Governance is an old word that goes back to Plato. The concept disappeared for a while, and was replaced by ideas like government, and government policy. Governance has now returned to the scene. Today, it is focussed on issues like participative democracy and transparency.

The state is no longer a unique partner in regulating systems. Other actors take part at the local, regional, national, and international levels. New means of regulating scientific, technical, and other subsystems, and new ways of communicating, are possible among a variety of actors and subsystems.

Internet governance has been a highly debated issue throughout the early part of the first decade of the twenty-first century, particularly at the World Summit on 
Information Systems (WSIS), held in Geneva in 2003 and in Tunis in 2005. The proposal to set up a Working Group on Internet Governance (WGIG) was adopted by government negotiators in Tunis. It put forward a multi-stakeholder approach to Internet governance. Stakeholder engagement has since become increasingly strong.

These debates raised other questions, particularly with regard to the role of business as a stakeholder. Even if the word "government" seems familiar, "civil society" and the "private sector" are perhaps less well defined. "Civil society" can be defined rather simply in the spirit of the philosopher Jürgen Habermas. Alternatively, it may be given more extensive definitions that invite discussions on precisely which kinds of organisations should be among the participants in civil society, and the extent to which business should be involved.

The main goal of the track Ethics and ICT Governance is to offer a forum to establish ICT governance as a new field in the discourse on computing ethics. The track continues the work of IFIP's SIG 9.2.2 Ethics of Computing, which has been working in this domain for almost 20 years. The group has produced various books and monographs on the ethics of computing. Yet it recognises that the current literature and guidelines could be enhanced and expanded upon, which has been the motivation behind the organisation of this track.

The contributions selected for this book discuss piracy, community empowerment, the digital divide, public procurement, ICT standardisation, money laundering and ethical governance for emerging ICTs. Jacques Berleur, Diane Whitehouse, Philippe Goujon and Catherine Flick introduce the theme of these contributions in detail in chapter 2 , embedding them in a broader debate on ethics and governance.

\subsection{Virtual Technologies and Social Shaping}

The track Virtual Technologies and Social Shaping, coordinated by the IFIP Working Group on Virtuality and Society (IFIF WG 9.5), focuses on the feedback loops between virtual technologies and the social groups who use them, how each of them shapes the other and in turn is shaped by them.

Social shaping, the sociology of technology, science studies and other approaches of cultural studies to the phenomenon of the information society, driven by such classics as those of Bijker and Law [4] and Mackenzie and Wajcman [6] are arguably now ready to be given a fresh look in the context of virtual environments and global social networking and gaming communities. The intervening years have additionally seen an explosion of digital and media arts interpretations, and explorations of the impact of virtual technologies upon society, and the social use of such technologies upon their design, and entrepreneurial trajectories of their appearance in the global market.

Virtual technologies, crucially, have moved very decisively from the workplace whether corporate or home office - into the domestic sphere, into our living rooms, playrooms, our kitchens, and our bedrooms. Here the relationship between virtual technologies and society, and the mutual shaping processes each of them undergoes, are ripe for fresh study, insight, and exploration.

The track addresses the choices faced by an information society permeated by ubiquitous virtual technologies, in which technology shapes social interactions, and society shapes technology. New identities and organisational forms emerge, huge 
volumes of information demand new strategies to cope with them, and issues of intellectual propriety rights become more important. In chapter 10, David Kreps gives a more detailed introduction to this track.

\subsection{Surveillance and Privacy}

New technical and legal developments are posing greater and greater privacy dilemmas. Governments have in the recent years increasingly established and legalised surveillance schemes in form of data retention, communication interception or CCTVs purportedly for fighting terrorism or serious crimes.

Surveillance monitoring of individuals is also a threat in the private sector: private organisations are, for instance, increasingly using profiling and data mining techniques for targeted marketing, analysing customer buying preferences or social sorting. Work place monitoring practices comprise surveillance of employees. Emerging pervasive computing technologies, where individuals are usually unaware of a constant data collection and processing in their surroundings, will further exacerbate the problem that individuals are effectively losing control over their personal spheres.

At a global scale, Google Earth and other corporate virtual globes may have dramatic consequences for the tracking and sorting of individuals. With CCTV, the controlling power of surveillance is in few hands. With live, high resolution imagery feeds from space in the near future, massive surveillance may soon be available to everybody, a development whose consequences we do not yet grasp. New means of surveillance are also enabled by social networks, in which individuals are publishing many intimate personal details about themselves and others. Such social networks are today already frequently analysed by employers, the marketing industry, law enforcement or social engineering.

The track Surveillance and Privacy, coordinated by the IFIP Working Groups on Computers and Social Accountability, and Information Technology Misuse and the Law (WG 9.2 and 9.6/11.7), aims to explore and analyse such privacy risks of surveillance for humans and society as well as countermeasures for protecting the individuals' rights to informational self-determination from multi-disciplinary perspectives. In chapter 16, Yola Georgiadou and Simone Fischer-Hübner highlight the main contributions of the articles in this track.

\subsection{ICT and Sustainable Development}

ICTs are perceived both as enablers of societal change towards sustainable development and as drivers of unsustainable resource consumption. How can we use ICTs to support management techniques which permit corporations, governments and societies to contribute to sustainable development?

Starting with ICT hardware, the relevant debates focus on the qualities and quantities of the material and energy flows caused by the life cycle of devices and how their relevance to sustainable development can be assessed. For example, there are increasing environmental and social implications of electronic waste (e-waste) building up in both industrialized countries and emerging economies. Since the production of an ICT device requires quantities of more than half the elements listed in the periodic system, the demand for scarce chemical elements for ICT is expected to grow. Assessing and 
reducing the energy and materials demand of ICT infrastructures per unit of service (Green IT) is therefore an important topic.

Much greater impacts - both in the positive and negative senses - with regard to sustainability can be caused by using ICT as an enabling technology for optimizing or being substituted for other technologies and processes. Researchers and practitioners alike are looking for solutions to apply ICT for higher energy and materials efficiency in production and consumption processes. Which applications might trigger a structural change towards a sustainable economy in the long run, and under what conditions might this be possible? A major issue under investigation is the application of ICTs for a reduction in greenhouse gas emissions and to facilitate adaptation to climate change, a topic that demands coordination on the local, national and global levels. ICTs are to be involved in the development of sustainable production, the improvement of resource productivity and economic dematerialization (decoupling total material consumption from GDP).

This track, coordinated by the IFIP Working Group on ICT and Sustainable Development (WG 9.9), will explore how information technology may indeed contribute to sustainable practices and processes in contemporary societies. In chapter 22, Lorenz Hilty and Magda Hercheui introduce the current discussion on ICT and sustainable development, presenting different views and conceptual frameworks related to this debate in a broad arena, and positioning the contributions of HCC9 within the debate on the role of ICT in sustainable development.

\section{References}

1. Avgerou, C., Smith, M.L., Besselaar, P.v.d. (eds.): Social Dimensions of Information and Communication Technology Policy, Proceedings of the 8th International Conference on Human Choice and Computers (HCC8), IFIP TC 9, Pretoria, South Africa, September 2526. Springer, New York (2008)

2. Berleur, J., Drumm, J. (eds.): Information Technology Assessment: Human Choice and Computers 4, Proceedings of the 4th IFIP-TC9 International Conference on Human Choice and Computers (HCC4), Dublin, July 8-12. Elsevier/North-Holland, Amsterdam (1991)

3. Berleur, J., Nurminen, M., Impagliazzo, J. (eds.): Social Informatics: An Information Society for All? Human Choice and Computers 7, Proceedings of the 7th IFIP-TC9 International Conference in Remembrance of Rob Kling, Maribor (Slovenia), September 21-23. Springer Science \& Business Media, Heidelberg (2006)

4. Bijker, W., Law, J. (eds.): Shaping Technology / Building Society: Studies in Sociotechnical Change. MIT Press, Cambridge (1992)

5. Brunnstein, K., Berleur, J. (eds.): Human Choice and Computers, Issues of Choice and Quality of Life in the Information Society, Proceedings of the 6th IFIP-TC9 Conference HCC6, at the 17th World Computer Congress, Montreal. Kluwer Academic Publ., Dordrecht (August 2002)

6. Mackenzie, D., Wajcman, J. (eds.): The Social Shaping of Technology. Open University Press, Buckingham (1985)

7. Mowshowitz, A. (ed.): Human Choice and Computers 2, Proceedings of the 2nd IFIP-TC9 Human Choice and Computers Conference (HCC2), Baden (Austria), June 4-8, 1979. Elsevier/North-Holland, Amsterdam (1980) 
8. Mumford, E., Sackman, H. (eds.): Human Choice and Computers, Proceedings of 1st Conference on Human Choice and Computers (HCC1), Vienna (Austria), April 1-5, 1974. Elsevier/North-Holland, Amsterdam (1975)

9. Rasmussen, L.B., Beardon, C., Munari, S. (eds.): Computers and Networks in the Age of Globalization, Proceedings of the 5th IFIP-TC9 Human Choice and Computers International Conference (HCC5). Kluwer Academic Publishers, Boston (2000)

10. Sackman, H. (ed.): Comparative Worldwide National Computer Policies, Proceedings of the 3rd IFIP-TC9 Conference on Human Choice and Computers (HCC3), Stockholm, Sweden, September 2-5, 1985. Elsevier/North-Holland (1986) 